vaccine, older volunteers and men tend to respond less well (unpublished findings). The important question of whether the vaccine is protective remains to be answered as studies are difficult to implement. Nevertheless, as human normal immunoglobulin is effective a vaccine that produces neutralising antibodies should also protect against disease.

Where and how will these vaccines be used? The World Health Organisation has incorporated hepatitis A into its programme for future vaccine development, since this vaccine would be of benefit to countries experiencing improved standards of hygiene and an increase in symptomatic hepatitis $A$ in young adults. In Shanghai in 1988, for example, there were 310746 reported cases of hepatitis A, $84 \%$ occurring in those aged 20-29."

In developed countries a vaccine would obviate the use of human normal immunoglobulin in, for example, members of the armed forces and travellers to endemic areas. Other high risk groups include people working with children, male homosexuals, and intravenous drug abusers. ${ }^{16}$ Food handlers may also be a group to be targeted as they are often the source of outbreaks. Whether an inactivated vaccine would reduce virus excretion, however, remains to be established.

Initially, the cost of a three dose course of inactivated hepatitis A vaccine is likely to be similar to that of hepatitis $B$ vaccine, reflecting high production costs and a poor yield of virus in cell cultures. In developing countries this would be unacceptably high, and techniques that produce a higher virus yield need to be developed. Alternatively, a live vaccine, which is likely to be cheaper, may be preferable in this setting. In developed countries, on the other hand, the inactivated vaccines currently on trial, despite their likely cost, would undoubtedly be used in preference to human normal immunoglobulin.

A J TILZEY

Senior Registrar in Virology JE BANATVALA

Professor of Clinical Virology

United Medical and Dental Schools of Guy's and St Thomas's Hospitals, St Thomas's Campus,

London SE1 7EH

1 Gruer LD, McKendrick MW, Beeching NJ, Geddes AM. Relapsing hepatitis associated with hepatitis A virus. Lancet 1982;ii: 163 .

2 Jacobson IM, Nath BJ, Dienstag JL. Relapsing viral hepatitis type A. 7 Med Virol 1985;16:163-9.

3 Clinical hepatitis A: laboratory reports years 1980-88. Communicable Disease Report 1990:89/46.

4 Banatvala JE, Thorogood RJ. Hepatitis A antibodies in London blood donors, medical students, and patients. Lancet 1980; ; 595.

5 Vandervelde EM, Millard JM, Parry JV, Mortimer PP. Time for action on hepatitis B

immunisation. BMF 1987;294:301.
6 Provost PV, Buynak EB, McLean AA, Hilleman MR, Scolnick EM. Progress toward a live $\overrightarrow{\overrightarrow{0}}$ attenuated human hepatitis A vaccine. In: Vyas GN, Fyrndysh JI, Hoffnagle JH, eds. Viral hepatitis and liver disease. Orlando: Grune and Stratton, 1984:467-75.

7 Provost PJ, Emini EA, Lewis JA, Gerety RJ. Progress toward the development of a hepatitis A vaccine. In: Zuckerman AJ, ed. Viral hepatitis and liver disease. New York: A R Riss Inc, 1988:83- O 6.

8 Ellis RW, Provost PJ. Hepatitis B and A vaccines. In: Zuckerman AJ, ed. Recent developments in prophylactic immunization. Dordrecht: Kluwer, 1989:181-209.

9 Flehmig B, Heinricy U, Pfisterer M. Prospects for a hepatitis A virus vaccine. Prog Med Virol N 1990;37:56-71.

10 Gust ID. Design of hepatitis A vaccines. Br Med Bull 1990;46:319-28

1 Mao JS, Dong DX, Zhang HY, Chon NL, Zhang MY, Huang HY, et al. Primary study of N attenuated live hepatitis A vaccine (H2 strain) in humans. F Infect Dis 1989;159:621-4.

12 Mao J. Development of live, attenuated hepatitis A vaccine (H2-strain). Vaccine 1990;8:523-4. Flehmig B, Heinricy U, Pfisterer $M$. Immunogenicity of a killed hepatitis A vaccine in seronegative $\mathcal{W}$
volunteers. Lancet 1989;i:1039-41.

Andre FE, Hepburn A, Hondt ED. Inactivated candidate vaccines for hepatitis A. Prog Med Virol 1990;37:72-95.

15 Wiedermann G, Ambrosch F, Kollaritsch H, Hofmann H, Kunz Ch, Hondt ED, et al. Safety and immunogenicity of an inactivated hepatitis A candidate vaccine in healthy adult volunteers. immunogenicity of a

16 Hepatitis A among drug abusers. MMWR 1988;37:297-301.

\title{
Non-operative management of blunt splenic injury
}

\section{Works well in about a quarter of patients}

Prompt splenectomy has traditionally been the treatment of choice for a spleen damaged by blunt abdominal trauma, but the wisdom of such an approach is being increasingly questioned. The risks and range of sepsis after splenectomy are now well defined, ${ }^{1}$ and a variety of options are available for preserving splenic function, including splenorraphy and partial splenectomy. ${ }^{2}$ There is also increasing evidence that some patients may not need surgery at all.

Non-operative management of blunt splenic injury in children is now a well accepted form of treatment in selected cases. In children particularly bleeding from the injured spleen has often stopped by the time laparotomy is performed. In 1968 paediatric surgeons in Toronto described 12 patients with suspected splenic injuries successfully managed without operation. ${ }^{3}$ By the mid-1980s about 260 children managed conservatively had been reported, with excellent results. ${ }^{4}$

Surgeons have been more reluctant to use selective nonoperative management in adults whose spleen has ruptured. This reluctance is undoubtedly partly due to the fact that sepsis after splenectomy is both less common and less dangerous in adults than in children. ${ }^{1}$ Also, changes in splenic architecture and vasculature with age ${ }^{56}$ and possible differences in the mechanisms of splenic injury between adults and children $^{7}$ may make the injured adult spleen less likely to stop bleeding spontaneously than a child's. These considerations, together with the possibility of missing associated injuries and fears of delayed rupture and the development of posttraumatic cysts or splenosis, still lead most surgeons to perform prompt splenectomy (or spleen preserving surgery) in adults.

Several recent reports, however, suggest that a sizeable proportion of adults with splenic injury after blunt trauma may be successfully managed without operation. Out of $45 \AA$ adults presenting with a ruptured spleen Klin et al selected 15 in a stable condition for conservative management, and none 윽 required operation. ${ }^{8}$ Villalba et al managed 34 out of 51 adult $N$ patients conservatively, only one requiring splenectomy, ${ }^{9}$ and $>$ Pachter et al managed 26 out of 146 conservatively, again with only one requiring surgery. ${ }^{10}$ Combining the results of these $N$ three studies suggests that about one in four patients could be $\underset{\omega}{N}$ managed conservatively, with a success rate of over $95 \%$. 으 These results contrast with less encouraging reports from 0 smaller earlier studies, in which a non-operative approach was successful in only one in four selected patients. ${ }^{711}$

To achieve the best results selection criteria must be strict. Patients suitable for non-operative management should be haemodynamically stable on admission or after initial resus- $\frac{\Omega}{\mathbb{Q}}$ citation. A ruptured spleen is usually suspected from clinical $\frac{\varrho}{\sigma}$ features suggestive of intra-abdominal bleeding and localised or generalised abdominal tenderness. The presence on plain $\delta$ radiography of fractured ribs overlying the spleen, an enlarged splenic shadow, and medial displacement of the gastric air bubble are also suggestive. Peritoneal lavage is often used to confirm the presence of intraperitoneal blood, and both ultrasound and laparoscopy are useful not only in confirming a splenic injury but also in helping to exclude other injuries. 
Most series of patients with splenic injury managed nonoperatively have, however, relied on scintiscanning or computed tomography to confirm splenic rupture definitively. Patients with injury due to penetrating trauma, with associated injuries requiring surgery, with serious head injury, or with coagulation disorders should not normally be considered for non-operative management, and some authors include alcohol intoxication as a contraindication. ${ }^{12}$

Most surgeons prefer to monitor selected patients initially in an intensive care setting, and patients should be managed with a nasogastric tube, intravenous fluids, and blood transfusion (if necessary) and assessed by frequent clinical examination and serial measurements of packed cell volume. Progressive abdominal signs usually indicate continuing haemorrhage or additional injuries. Non-operative management should be abandoned if haemodynamic stability is not maintained or multiple transfusions are required. Luna and Dellinger suggested that the long term risks of transfusion (based on estimates of the risks of transmission of hepatitis but not including the risks of transmission of AIDS) may exceed those of splenectomy,,$^{13}$ but many patients managed non-operatively require no transfusion at all, ${ }^{8}$ and in those who do it is often because of associated injuries. ${ }^{6}$ Successfully managed patients are gradually mobilised and are usually fit for discharge after 7-10 days. They should be advised to avoid strenuous physical activity and contact sports for several months. Follow up investigations usually show complete healing of the splenic defect. The spleen is important in host defence against malaria, ${ }^{14}$ and non-operative management has been successfully employed in a Third World setting without the benefit of intensive care facilities, splenic scans, or computed tomography. ${ }^{15}$
Up to one quarter of adults with splenic injury caused by blunt abdominal trauma may satisfy selection criteria for nonoperative management. Such management is successful in most cases, thus preserving splenic function. Such a policy must not, however, put any patient at risk; most adults with splenic rupture are still best served by prompt laparotomy, with spleen preserving surgery in suitable cases.

Registrar,

E J GIBNEY

Department of Surgery,

St Michael's Hospital,

Dun Laoghaire,

County Dublin,

Ireland

1 Shaw JHF, Print CG. Postsplenectomy sepsis. Br $\mathcal{F}$ Surg 1989;76:1074-81.

Cooper MJ, Williamson RCN. Splenectomy: indications, hazards, and alternatives. Br $\mathcal{f}$ Surg 1984;71:173-80.

3 Upadhyaya P, Simpson JS. Splenic trauma in children. Surg Gynecol Obstet 1968;126:781-90.

4 Zucker K, Browns K, Rossman D, Hemingway D, Saik R. Nonoperative management of splenic trauma. Arch Surg 1984;119:400-4.

Gross P. Zur kindlichen traumatischen Milzruptur. Beitr klin Chir 1964;208:396-402.

6 Morgenstern L, Uyeda RY. Nonoperative management of injuries of the spleen in adults. Surg Gynecol Obstet 1983;157:513-8.

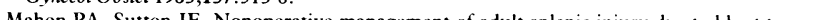
warning. Am f Surg 1985;149:716-21.

8 Klin B, Rivkind A, Krausz Y, Rabinovici R, Chisin R, Eyal Z Nonoperative management of blunt splenic trauma in adults. Int Surg 1990;75:50-3.

Villalba MR, Howells GA, Lucas RJ, et al. Nonoperative management of the adult ruptured spleen. Arch Surg 1990;125:836-9.

10 Pachter HL, Spencer FC, Hofstetter SR, et al. Experience with selective operative and nonoperative treatment of splenic injuries in 193 patients. Ann Surg 1990;211:853-91.

11 Malangoni MA, Levine AW, Droege EA, Aprahamian C, Condon RE. Management of injury to the spleen in adults. Results of early operation and observation. Ann Surg 1984;200:702-5.

12 Shackford SR, Molin M. Management of splenic injuries. Surg Clin North Am 1990;70:595-620.

13 Luna GK, Dellinger EP. Nonoperative observation therapy for splenic injuries: a safe therapeutic option? Am F Surg 1987;153:462-8.

14 Gibney EJ. Surgical aspects of malaria. Br f Surg 1990;77:964-7.

15 Papua New Guinea Splenic Injury Study Group. Ruptured spleen in the adult: an account of 205 cases with particular reference to non-operative management. Aust NZ f Surg 1987:57:549-53.

\section{Cervical samplers}

\section{Most important variable is probably the operator's skill}

The first cervical sampler for cytological diagnosis of cancer of the cervix was a platinum loop, used by the Romanian pathologist Babes in 1928. ${ }^{1}$ Cervical screening developed from the demonstration by Papanicolaou and Traut in 1941 that malignant change in the cervix could be diagnosed by examining cells aspirated from the vagina. ${ }^{2}$ In 1944 Ayre suggested improving the accuracy of the test by passing a speculum and aspirating mucus from around the external os. ${ }^{3}$ Later he advocated "surface biopsy" of the cervix, using a wooden spatula to sample small localised cancer lesions that might be invisible to the naked eye. ${ }^{4}$ This spatula, which bears his name, has a hook end and a rounded end. The hook end is for sampling the cervices of nulliparous women and cervices where the squamocolumnar junction is inside the endocervical canal. The rounded end is for sampling eroded and lacerated cervices and those of parous women.

Trials comparing these methods have found that scraping with an Ayre spatula is consistently better than the vaginal aspiration (false negative rate $0-16 \%$ compared with $8-69 \%$ ). ${ }^{5}$ Combining both procedures reduced the false negative rate still further. The successful screening programmes in British Columbia, Iceland, Aberdeen, and The Netherlands all used the Ayre spatula, and nearly 50 years after its introduction it is still in use. Increasing concern about invasive cancer being found after negative smear test results led to the development of many different cervical samplers, ${ }^{6}$ including tampons and sponges, ${ }^{7}$ various modifications to the hook end of the Ayre spatula in wood and plastic, ${ }^{8-11}$ a multivariate spatula, ${ }^{12}$ and brushes. ${ }^{13} 14$ The absence of good comparative trials of many of these samplers makes assessment of their relative merits difficult.

Many studies use the presence or absence of endocervical $N$ cells in the cervical smear as the sole measure of the adequacy $D$ of the sampler, although considerable disagreement exists over the usefulness of this criterion. ${ }^{15-20}$ Few would disagree $N$ with Koss that the only smears that can be judged with $\underset{\omega}{N}$ certainty as adequate are those that contain abnormal cells. ${ }^{15}$ 尺

One of the inherent problems in comparing differentco cervical samplers is the wide variation among people in their $\mathbb{D}$ ability to obtain representative samples. In experienced hands? false negative results of sampling with an Ayre spatula are nearly all due to small lesions occupying two quadrants or less $\mathbb{D}$ of the cervix. These are usually cervical neoplasms grade I or $\mathbb{\otimes}$ II. ${ }^{21}$ Two studies from genitourinary clinics suggest that in young women, when the smear takers are experienced, the type of sampler does not make any difference to the detection rate of abnormal smears..$^{22}$

Several studies have shown that two samples taken at the 을 same time are better than one, whether the same or different samplers are used. ${ }^{24}{ }^{25}$ The effectiveness of the cytobrush, an endocervical brush developed by Stormby, ${ }^{13}$ when used in conjunction with either an Ayre or a modified Ayre spatula, 